\title{
Discussion on Improving the Teaching Quality of Laser Technology
}

\author{
X. D. YU, K. Y. YANG, B. ZHANG \& J. YUAN \\ College of Optoelectronic Science and Engineering, National University of Defense Technology, Changsha, \\ 410073, China
}

\begin{abstract}
Laser technology is an important professional technical course for undergraduate in optical engineering. The basic content of Laser technology is introduced firstly. Combining the teaching process, the teaching experiences are described in detail. The introduction class should play a more important role to inspired students' interest and basic theory and technology should combine closely. The course should train research consciousness by research project and improve teaching methods to mobilize their enthusiasm and passion for learning. These methods can also encourage students to better understand and master the teaching content of the course. These are helpful for establishing a good foundation for their future use and development of lasers.
\end{abstract}

KEYWORD: Laser technology; teaching quality; teaching reform

\section{INTRODUCTION}

Since the birth of the laser since the sixties of last century, laser technology has made rapid progress and its application has increasingly penetrated into industrial and agricultural production, scientific research, defense, energy, medicine, art and other aspects of daily life [1-3].

In energy area, research on laser controlled nuclear fusion of the world is in the ascendant, and laser technology and information technology promote the development of laser holography, laser communications and laser storage; In military area, the laser has been used on laser radar, laser guidance and a variety of strategies or tactical laser weapons; In medical area, laser has accessed to critical applications such as laser cosmetic, laser scalpels; In industrial area, laser alignment, laser navigation, laser processing, surface modification and laser forming have been well known; In scientific research, it can provide extreme physical conditions, as an advanced light source which can also be used as a proton acceleration, high-order harmonic generation and other applications. In view of the laser optics are widely used in national defense, industrial, civil and scientific and other fields, it is listed as a national strategy to support technology.

\section{TEACHING CONTENT}

Laser technology is a very important professional and technical course for optical engineering undergraduates. The course is devoted to basic techniques involved in the process of laser applications. We use the "laser technology" as book edited by X.J. Lan in third edition [4]. This course introduces the basic principles and the various implementation methods of laser technology. The contents include laser modulation and deflection technique, Q-switched technology, ultrashort pulse technology, laser amplification technology, selected frequency and mode selection technique, frequency stabilization technology and so on. A total of six chapters are 38 hours, the course content has a very strong engineering features. In the process of teaching the course, we have a special focus on curriculum theory and research knowledge combined with practical work and achieved good teaching results.

\section{TEACHING PRACTICE AND EXPLORATION}

\subsection{Play a more important role in introduction class to inspired students' interest}

The content of this course is highly theoretical, conceptual and abstract. So inspiring student learning enthusiasm and initiative is particularly important. In the introduction class, we should 
address the student's curiosity about new things and exploring the psychological and make full use of instance, multimedia, visual resources to appreciate the funny and practicality for this course. Introduction lesson is the first lesson of this course, the course will have a direct effect on the subsequent teaching and introduction is the most important part in the construction of curriculum. In order to fully mobilize the enthusiasm of the students of this course, I teach the introduction from the following aspects to achieve the desired aims of teaching. A good introduction is a key to open the door to help students to learn new subjects, to correct a one-sided view of the minds, to renewal and establish the principle of laser.

When introducing laser applications, I give more interesting examples to stimulate students interesting, such as, tactical laser weapons and strategic laser weapons in military applications, laser welding, laser cutting, laser marking, laser rapid prototyping in industrial applications, laser treatment of skin, disease and myopia in medicine applications, When introducing the classification of laser, I list gas lasers, solid-state lasers, dye lasers, semiconductor lasers by substance category, and also nanosecond lasers, picosecond lasers, femtosecond lasers and attosecond lasers by pulse length category. Combined the latest research progress of the femtosecond lasers and attosecond lasers, the forefront applications in micro-nanofabrication, laser rangefinder, laser storage are introduced.

\subsection{Combine basic theory and technology closely}

For a long time, teaching content for laser technology focuses on the basic principles and theory. Theory conclusion is generally obtained through complex mathematical derivation, it is abstract for students and makes learning boring. Basic theory should be closely linked with techniques. Laser technology is opened after laser principle, physical optics and optical technology. The teaching process is inseparable from the basic course. Firstly, in the process of laser technology, the design can not be separated with the specific optical system such as the light collecting system, the beam homogenization system and various spectral system designs. It must apply the principles of geometric optics and optical design software. Secondly, in the laser transfer technique, diffraction will occur while the laser light passes through the air medium or various kinds of optical elements, resulting in a decline and loss of light energy in the beam quality. This part of the knowledge needed to be explained by the relevant principles of physical optics. Therefore, in the teaching process we must consolidate the new curriculum teaching with the basics principle.

\subsection{Contact teaching with research to train research quality}

Teaching and research are two basic tasks of our university teachers. Only teaching is not conducive to improve the professional level, in the long run, it will not keep up with the pace of technological progress, teaching will therefore become boring and unconvincing. Therefore, in order to improve teaching effectiveness and persuasive, you must complete the task of teaching, and while actively engaged in related research. In the classroom, if we can appropriately throughout their research on classroom teaching, it will increase the effectiveness of classroom teaching and persuasive $[5,6]$.

For example, in 2009, a 629nm He-Ne laser is needed as light source for doctor dissertation [7]. The gain spectrum of $629 \mathrm{~nm}$ is too weak so we can not found suitable laser on the international market. The weak oscillation in He-Ne laser is observed only in long external cavity which the cavity length is more than one meter, and also mixed with the high gain laser oscillation spectrum 633nm. To manufacture the $629 \mathrm{~nm} \mathrm{He}-\mathrm{Ne}$ laser, in the beginning, we tried several conventional laser line selection methods but all failure. In the teaching process of laser technology, the author taught selection of a single longitudinal mode laser oscillation by Fabry-Perot cavity in the chapter of selected frequency and mode selection techniques. This principle gives us an original idea. Inspired by this principle, a method to choose weak laser oscillation spectrum by Fabry-Perot cavity is proposed. A whole structure of the cavity lumen $629 \mathrm{~nm}$ singlet helium-neon laser is manufactured which output power reach $150 \mathrm{~mW}$ and the length is only $250 \mathrm{~mm}$. It is unique in the world.

\subsection{Improve teaching methods}

Course teaching uses multimedia courseware flexibly to explain or demonstrate the basic theory and techniques. According to the teaching content and course characteristics, the formula and some abstract and difficult theoretical knowledge are downplayed. We design the PPT slides and add flash animation for some device and phenomenon, which are vivid intuitive and easy to understand.

The multimedia which is vivid, fast and efficient, informative, convenient and flexible, process virtualization greatly stimulates the students' interest and enthusiasm for learning. For example, when talking about the electro-optic effect, a flash of the output for the electro-optic crystal is demonstrated. The intensity and amplitude of ordinary light and extraordinary light along optics path are animated, which not only demonstrate physical process, also make the learning easy to understand. In addition, we make full use of the network to download relevant courseware, so students can take advantage 
of network resources for preparation, self-study and review. In the classroom, they can pay more attention in the contents which are not understood.

\section{CONCLUSIONS}

The teaching content and features of laser technology course are analyzed and teaching practice and exploration are discussed from four aspects. The introduction class should play a more important role to inspired students' interest and basic theory and technology should combine closely. The course should train research consciousness by research project and improve teaching methods to mobilize their enthusiasm and passion for learning. These methods can help to improve teaching quality.

\section{REFERENCES}

[1] Siegman A.E. 1986. Lasers, Oxford University Press.

[2] Silfvast W.T. 2004. Laser Fundamentals (Second Edition), Cambridge University Press.

[3] Svelto O.1998. Principles of Lasers (Fourth Edition), Plenum Press (New York and London).

[4] Lan X.J. 2009. Laser technology (Third Edition), Science Press.

[5] Hu S.M., Luo H. 2012. Some Experience in Teaching "Principles of Lasers", Journal of Higher Education Research, 35(3): 71-73.

[6] Zhang B., Yang K.Y., Yuan J. 2011. Teaching experience in laser technology based on the organic unity of teaching and research. Heman Science and Technology, 7: 27-28.

[7] Liang J., Long X.W., Zhang B., Jin S.L. 2009. Spectral Selection in He-Ne Laser by Internal F-P Etalon, Acta Optica Sinica, 29(11): 3108-3113. 